\begin{tabular}{|c|c|c|}
\hline Case Reports in & \multicolumn{2}{|c|}{ Case Rep Gastroenterol 2018;12:473-478 } \\
\hline Gastroenterology & $\begin{array}{l}\text { DOI: } 10.1159 / 000492213 \\
\text { Published online: August 23, } 2018\end{array}$ & $\begin{array}{l}\text { (c) } 2018 \text { The Author(s) } \\
\text { Published by S. Karger AG, Base } \\
\text { www.karger.com/crg }\end{array}$ \\
\hline & $\begin{array}{l}\text { This article is licensed under the } \\
\text { International License (CC BY-NC) } \\
\text { Usage and distribution for commer }\end{array}$ & $\begin{array}{l}\text { nons Attribution-NonCommerci } \\
\text { ger.com/Services/OpenAccessLic } \\
\text { uires written permission. }\end{array}$ \\
\hline
\end{tabular}

\title{
A Case of Gastroparesis after Cryoballoon Ablation followed by Medication-Induced Recovery within 6 Months
}

\author{
Yukie Sunata $^{\mathrm{a}}$ Hideki Mori $^{\mathrm{a}}$ Yuichiro Hirai ${ }^{\mathrm{a}}$ Yoko Kubosawa ${ }^{\mathrm{a}}$ \\ Shigeo Banno ${ }^{a}$ Satoshi Kinoshita ${ }^{a}$ Yoshihiro Nakazato ${ }^{a}$ \\ Toshihiro Nishizawa ${ }^{a}$ Masahiro Kikuchi ${ }^{a}$ Toshio Uraoka ${ }^{a, b}$ \\ ${ }^{a}$ Department of Gastroenterology, National Hospital Organization Tokyo Medical Center, \\ Tokyo, Japan; 'bivision of Gastroenterology and Hepatology, Department of Internal \\ Medicine, Gunma University Graduate School of Medicine, Maebashi, Japan
}

\section{Keywords}

Gastroparesis · Cryoballoon ablation · Atrial fibrillation · Delayed gastric emptying

\begin{abstract}
Atrial fibrillation (AF) is the most common cardiac arrhythmia, and cryoballoon ablation was developed as a new treatment modality for symptomatic AF. Gastroparesis is rarely reported as a transient complication of ablation, and its frequency and risk are not clear. We experienced a rare case of gastroparesis after cryoballoon ablation followed by medication-induced recovery within 6 months.

(C) 2018 The Author(s) Published by S. Karger AG, Basel
\end{abstract}

\section{Introduction}

Atrial fibrillation (AF) is the most common cardiac arrhythmia, and 1-3\% of the general population have it [1]. Conventional catheter ablation was performed with point-by-point radiofrequency ablation for pulmonary vein isolation. Cryoballoon ablation was developed as a new treatment modality for symptomatic AF. This treatment uses a cryoballoon with nitrogen 
monoxide to isolate the pulmonary vein by coagulative necrosis so that we can make circular damage of the pulmonary vein at once. Therefore, it is thought to be safer and easier to perform than conventional radiofrequency catheter ablation [2]. However, some major complications of ablation were reported, such as tamponade, stroke, phrenic nerve paralysis, pulmonary vein stenosis, and atrioesophageal fistula formation [3]. Also, gastroparesis is rarely reported as a complication of ablation, but the accurate frequency and risk is not clear because X-ray, computed tomography, or esophagogastroduodenoscopy are not performed without symptoms. Here we present a rare case of gastroparesis after cryoballoon ablation who recovered with medication within 6 months.

\section{Case Presentation}

A 78-year-old man who had experienced a myocardial infarction many years previously underwent cryoballoon ablation treatment for symptomatic AF. There were no gastrointestinal symptoms before the ablation and no gastric dilatation was confirmed by X-ray (Fig. 1a). Three days later, he visited our hospital and complained of abdominal fullness and constipation. A blood test showed no apparent abnormalities. His abdominal X-ray showed a big amount of food residue in his stomach (Fig. 1b). We prescribed magnesium oxide and mosapride citrate hydrate, but the symptoms did not improve. Computed tomography showed marked gastric dilatation without any intestinal obstruction. Esophagogastroduodenoscopy was also performed and revealed a big amount of food residue, despite the fact that $16 \mathrm{~h}$ had passed from the last meal (Fig. 2a). Upper gastrointestinal series also revealed severe gastroparesis (Fig. 3). He was started on vonoprazan fumarate (a novel potassium-competitive acid blocker) and Rikkunshito (a Japanese herbal medication). His symptoms of abdominal fullness did not completely improve until 5 months after treatment, although abdominal X-rays continued to show residual food in his stomach $16 \mathrm{~h}$ after his last meal. This symptom, however, gradually improved, and his gastroparesis was cured 6 months after cryoballoon ablation (Fig. 1b-d, Fig. 2b).

\section{Discussion}

Gastroparesis is defined as delayed gastric emptying without mechanical obstruction of the stomach. The symptoms are abdominal fullness, nausea, and vomiting. There is no clear diagnosis criterion, so we have to exclude organic disease by endoscopy and imaging tests such as X-ray, computed tomography, and gastrointestinal series. A blood test is also useful to exclude electrolyte abnormality, diabetes, and dysfunction of the thyroid gland.

The major causes of gastroparesis are postsurgical, diabetes, idiopathic, and drugs such as anticholinergics, opioids, levodopa, tricyclic antidepressants, and phenothiazines [4]. Gastroparesis can also occur following radiofrequency catheter ablation. Gastroparesis after catheter ablation has been associated with periesophageal vagal plexus injury, which may be avoided by monitoring of esophageal temperature [5]. Some patients have been reported to experience gastroparesis after cryoballoon ablation, with all of these patients recovering from symptoms within 2 months [6]. Therefore, the mechanism by which cryoballoon ablation induces gastroparesis is thought to involve reversible damage to the nerve resulting from transient coagulation. The cause of gastroparesis in our patient was unclear because his esophageal temperature was monitored appropriately. Moreover, the duration of gastroparesis in 
this patient was 6 months. These characteristics suggest that unknown factors may have affected the pathogenesis of gastroparesis in this patient. Prospective studies are required to assess the details of gastroparesis induced by cryoballoon ablation.

\section{Statement of Ethics}

The authors have no ethical conflicts to disclose.

\section{Disclosure Statement}

The authors have no conflicts of interest to disclose.

\section{Author Contributions}

All authors were involved in the clinical management of and communication with the patient, and all were involved in the design of the study. Y. Sunata drafted the manuscript and $\mathrm{H}$. Mori made contributions to the manuscript. All authors approved the submission of the final draft.

\section{References}

1 Benjamin EJ, Wolf PA, D'Agostino RB, Silbershatz H, Kannel WB, Levy D. Impact of atrial fibrillation on the risk of death: the Framingham Heart Study. Circulation. 1998 Sep;98(10):946-52.

2 Packer DL, Kowal RC, Wheelan KR, Irwin JM, Champagne J, Guerra PG, et al.; STOP AF Cryoablation Investigators. Cryoballoon ablation of pulmonary veins for paroxysmal atrial fibrillation: first results of the North American Arctic Front (STOP AF) pivotal trial. J Am Coll Cardiol. 2013 Apr;61(16):1713-23.

3 Bhat T, Baydoun H, Asti D, Rijal J, Teli S, Tantray M, et al. Major complications of cryoballoon catheter ablation for atrial fibrillation and their management. Expert Rev Cardiovasc Ther. 2014 Sep;12(9):1111-8.

4 Masaoka T, Tack J. Gastroparesis: current concepts and management. Gut Liver. 2009 Sep;3(3):166-73.

5 Kuwahara T, Takahashi A, Kobori A, Miyazaki S, Takahashi Y, Takei A, et al. Safe and effective ablation of atrial fibrillation: importance of esophageal temperature monitoring to avoid periesophageal nerve injury as a complication of pulmonary vein isolation. J Cardiovasc Electrophysiol. 2009 Jan;20(1):1-6.

6 Miyazaki S, Nakamura H, Taniguchi H, Hachiya H, Takagi T, Igarashi M, et al. Gastric hypomotility after second-generation cryoballoon ablation - unrecognized silent nerve injury after cryoballoon ablation. Heart Rhythm. 2017 May;14(5):670-7. 


\section{Case Reports in Gastroenterology}

\begin{tabular}{l|l}
\hline Case Rep Gastroenterol 2018:12:473-478 \\
\hline DOI: 10.1159/000492213 & $\begin{array}{l}\text { @ 2018 The Author(s). Published by S. Karger AG, Basel } \\
\text { www.karger.com/crg }\end{array}$ \\
\hline
\end{tabular}

Sunata et al.: Gastroparesis after Cryoballoon Ablation
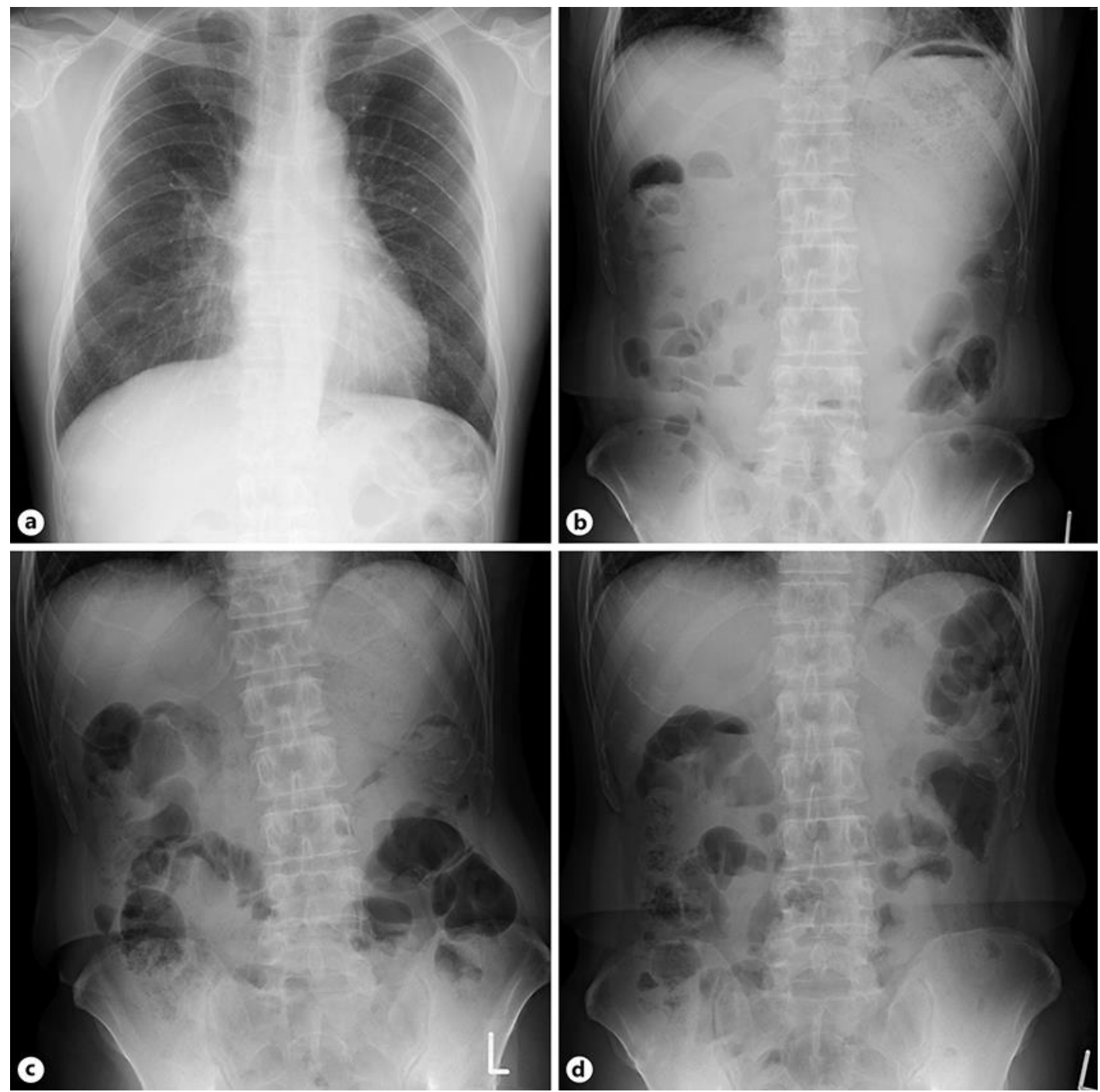

Fig. 1. X-rays of the patient. a Chest X-ray before ablation showing no food residue in the stomach. b-d Abdominal X-rays 3 days (b), 5 months (c), and 6 months (d) after ablation. Residual food was present in the stomach at 3 days and 5 months, but not at 6 months after ablation. 


\section{Case Reports in \\ Gastroenterology}

\begin{tabular}{l|l}
\hline Case Rep Gastroenterol 2018;12:473-478 \\
\hline DOI: 10.1159/000492213 & $\begin{array}{l}\text { ○ 2018 The Author(s). Published by S. Karger AG, Basel } \\
\text { www.karger.com/crg }\end{array}$ \\
\hline
\end{tabular}

Sunata et al.: Gastroparesis after Cryoballoon Ablation
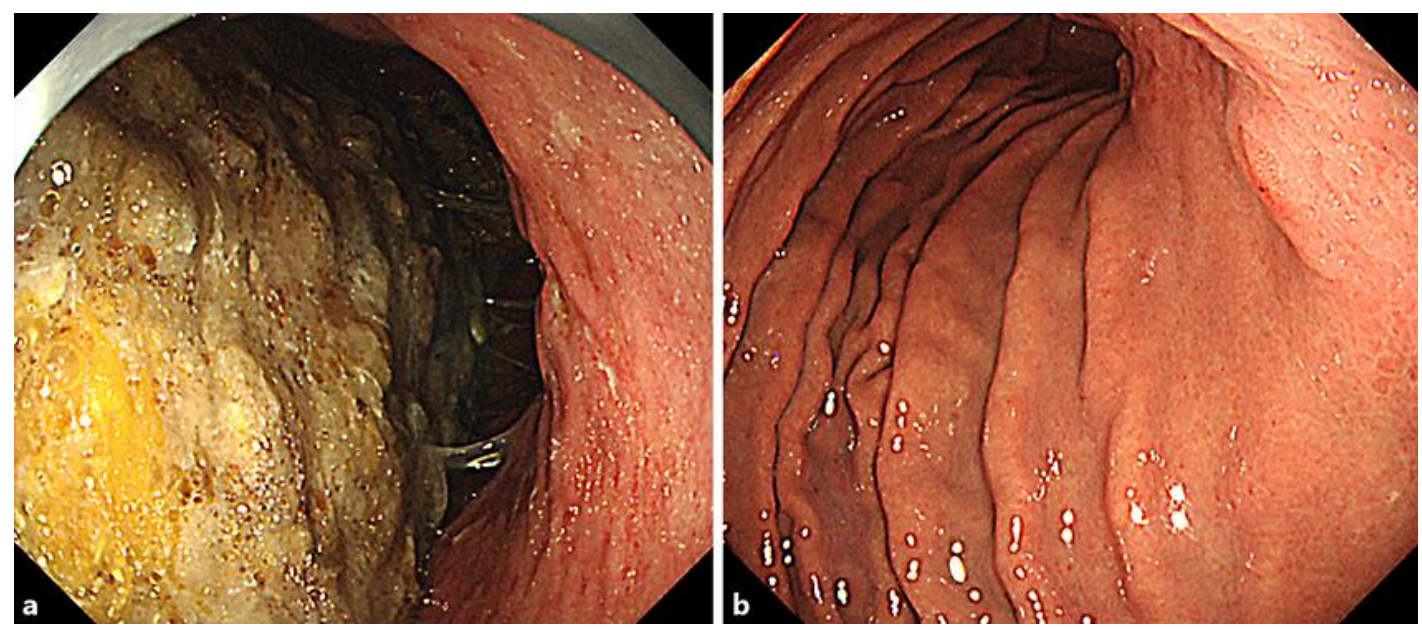

Fig. 2. a Esophagogastroduodenoscopy performed 17 days after the ablation, showing a large amount of food residue in the stomach $16 \mathrm{~h}$ after the patient's last meal. b Six months after the ablation there was no food residue in the stomach. 


\begin{tabular}{|c|c|c|}
\hline \multirow{2}{*}{$\begin{array}{l}\text { Case Reports in } \\
\text { Gastroenterology }\end{array}$} & \multicolumn{2}{|c|}{ Case Rep Gastroenterol 2018;12:473-478 } \\
\hline & DOI: 10.1159/000492213 & $\begin{array}{l}\text { O } 2018 \text { The Author(s). Published by S. Karger AG, Basel } \\
\text { www.karger.com/crg }\end{array}$ \\
\hline
\end{tabular}

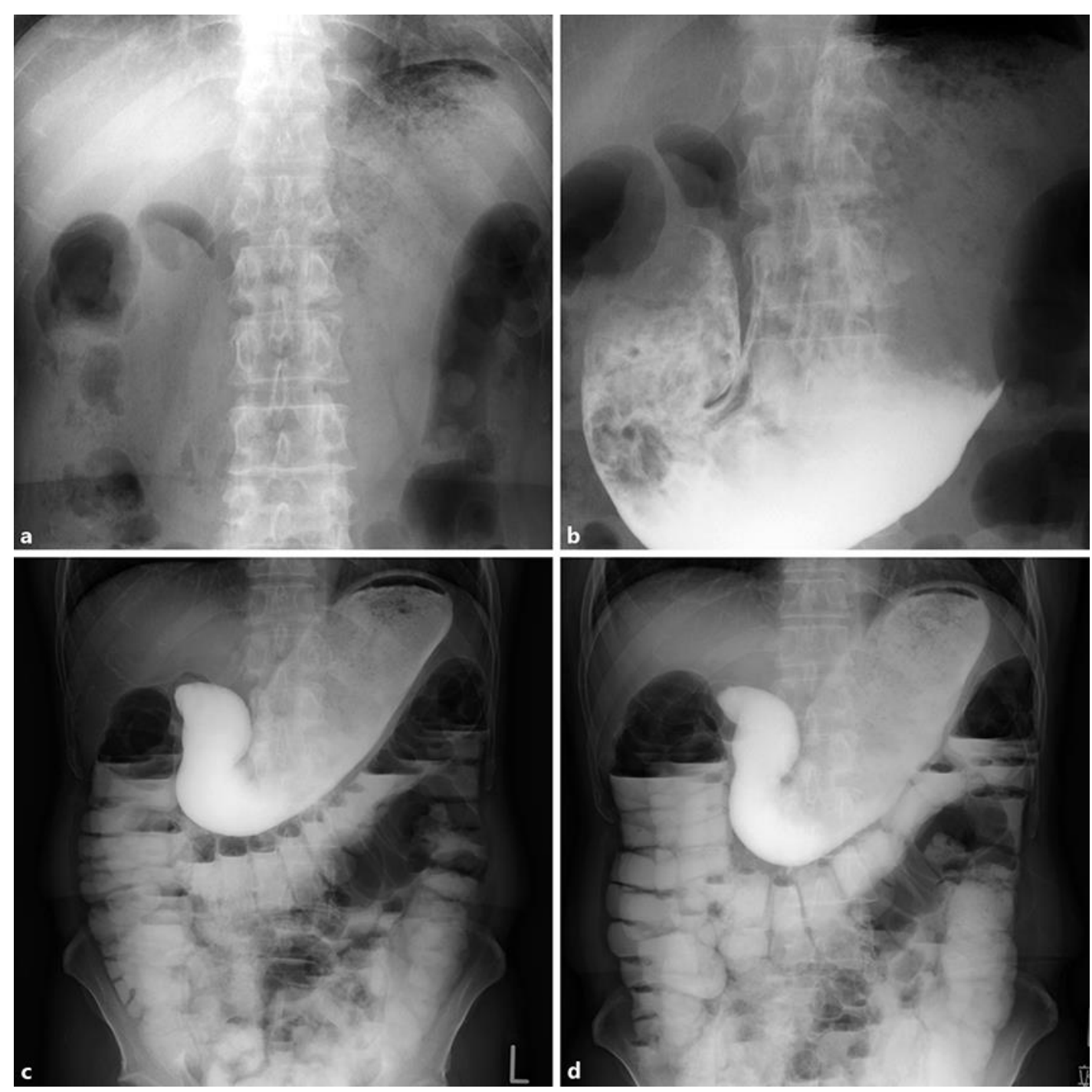

Fig. 3. Gastrointestinal X-ray series performed 33 days after ablation prior to taking the contrast agent (a) and immediately (b), $1 \mathrm{~h}(\mathbf{c})$, and $2 \mathrm{~h}(\mathbf{d})$ after taking the contrast agent. Severe gastric dilatation and gastroparesis were observed, but the motility of the small intestine and colon was not affected. 